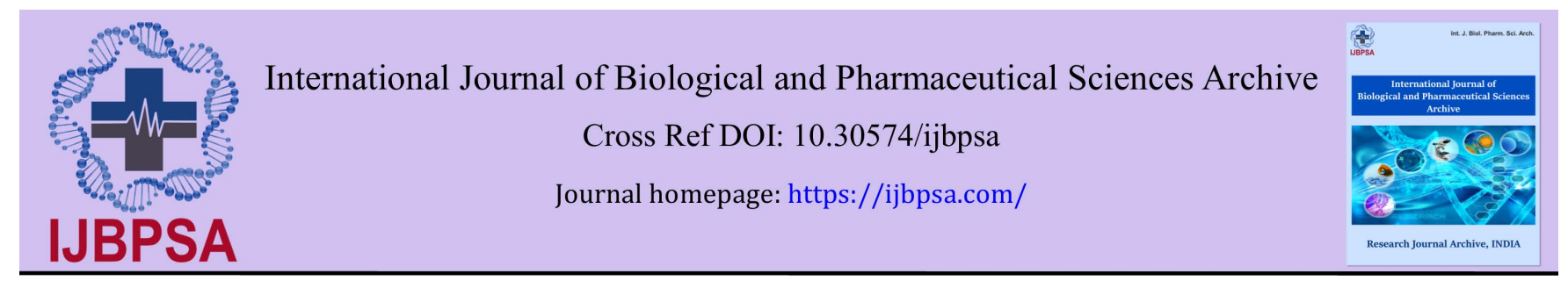

(RESEARCh ARTICLE)

\title{
The use of artificial intelligence in improving the preservation and quality of cashew apple juice drinks for national development
}

\author{
Salome Ojone Aniama * \\ Department of Biology, Federal College of Education, Okene, Kogi State, Nigeria.
}

International Journal of Biological and Pharmaceutical Sciences Archive, 2021, 01(02), 001-008

Publication history: Received on 04 January 2021; revised on 18 January 2021; accepted on 21 January 2021

Article DOI: https://doi.org/10.30574/ijbpsa.2021.1.2.0010

\begin{abstract}
The aim of this paper is to highlight on the use of artificial intelligence in improving the preservation and quality of cashew apple juice with an objective to reduce the astringency as well as microbial count, so that shelf life of the juice will be prolonged. Cashew apples are highly nutritious consisting of vitamins, organic acids, polyphenols, sugars, amino acids and minerals. Although cashew fruits are in abundance, their utilization is limited due to astringency and rapid microbial deterioration. The effects of clarification, sterile filtration and chemical preservation were investigated. The juice from the cashew apple was extracted using mechanical juice extractor with stainless metal. The extractor had an average efficiency of $80 \%$. Three samples of the juice (fresh juice, juice stored under ambient conditions for 24 hrs and refrigerated juice at $5{ }^{\circ} \mathrm{C}$ ) were tested for sensory evaluation. The results showed a significant difference (p<0.05) between the colour, taste and general acceptability of juice under ambient storage when compared with fresh juice; but there was no significant difference in the mouth feel. There was no significant difference between the colour, taste and mouth feel of the refrigerated juice and fresh juice. The physico-chemical characteristics show that appearance, specific gravity, $\mathrm{pH}$ and total soluble solids of the juice are affected significantly $(\mathrm{p}<0.05)$ by storage under ambient conditions but only the specific gravity changed significantly $(\mathrm{p}<0.05)$ during refrigeration. The vitamin $\mathrm{C}$ content of the refrigerated juice was higher than juice stored under ambient conditions and the juice can be preserved safely under refrigeration up to three months. Mechanical juice extractor should be used in extracting juice as this will reduce wastage and contamination of the products.
\end{abstract}

Keywords: Artificial Intelligence; Cashew Apple; National Development; Clarification

\section{Introduction}

Cashew (Anacardium Occidentale L.) is an important hard, drought-resistant, tropical economic tree crop which thrives well virtually in all vegetation belts of Nigeria, but grows better in the guinea savanna. Originally, according to [1], Cashew a native of Brazil, was introduced to other parts of the world starting from the $16^{\text {th }}$ century mainly with the intention of afforestation and soil conservation. From its humble beginning as a crop intended to check soil erosion, cashew has come out as a major foreign exchange earner in most of the countries. Cashew apple is a pseudo-fruit rich in reducing sugars (fructose and glucose), vitamins mainly vitamin C (170-350 mg/100 g), minerals, some amino acids, polyphenols, organic acids, carbohydrates and pigments [2, 3], in fact it contains five times more vitamin $C$ than an orange and contains more calcium, iron and vitamin B1 than other fruits such as citrus, avocados and bananas [4], it also possess anti-microbial and anti-mutagenic activities [5, 6]. The juice can be utilized as substrate for the production of dextransucrase, ethanol, biosurfactant, hyaluronic acid, mannitol and many other value added products [7, 8, 9, 10, 11]. The apple is highly perishable but very healthy. It can be eaten fresh or juiced and can be processed industrially into a variety of products such as Syrup, canned fruits, pickles, jams, chutneys, candies, toffees, ice creams, vinegar, marmalade and distilled products such as wine, brandy, gin $[12,13]$. About $90 \%$ of the cashew apples production is lost

\footnotetext{
*Corresponding author: Aniama Salome Ojone (Ph.D); E-mail: salomeaniama@yahoo.com

Department of Biology, Federal College of Education, Okene, Kogi State.
} 
in the field after removing the nut, this wastage of cashew apples is mainly attributed to short shelf life and rapid microbial action [14]. Unlike other fruit juices, the juice extracted from cashew apple cannot be consumed frequently or "any how" due to its characteristic astringent taste, which causes biting sensation of the tongue and throat limiting the use of cashew apple as a table fruit. In order to decrease astringency and to prevent spoilage, it is essential to investigate a suitable method to process, improve and preserve the juice. Apart from the presence of astringent principles which limits its use in the raw form as well as processed product, cashew apple as a commodity has other limitations as well. It is highly susceptible to physical injury which leads to microbial spoilage within a very short period after harvest. The storability of cashew apple is thus very poor and complete spoilage can occur within hours after harvest. Ripe apples are also subjected to damage by insect and non-insect pests. The system of collection of cashew nuts from fallen fruits after considerable delay also limits the availability of quality cashew apple for processing purposes [15]. Preservation and shelf life evaluation have been carried out in various ways [3, 16, 17, 18, 19]. The use artificial intelligence becomes eminent which is the aim of this study.

Artificial Intelligence is the combination of theories, algorithms, and computing frameworks, facilitating various tasks that require human intelligence such as reasoning, decision-making, speech recognition, language understanding, and visual perception. Artificial Intelligence can help to significantly speed up a process and result in faster and better advised decision-making, Artificial Intelligence augments and complements, it is not a replacement for human intelligence and intuition, where its goal is to help humans become faster and smarter in certain tasks [20]. Artificial intelligence aims to mimic human cognitive functions [21,22]. The food processing industry is benefitting greatly from the latest advancements in artificial intelligence, which is doing everything from helping to sort foods, maintaining topnotch health and safety compliances, developing new products, and bolstering the supply chain. The technology is essentially helping to streamline work processes, making the work of employees easier and making operations more efficient [23]. The biggest advantage of the application of Artificial Intelligence in the food industry is that it would lessen human errors and the automated process would bring more quality to the product as well as reduce wastage. The ultimate aim would be to attain best quality services and products. Food and beverage industry are turning to implement Artificial Intelligence to achieve better, efficient and best results as food borne diseases are on the increase in industrialized countries and developing countries. The proportion of the population at high risk of illness or death from food borne pathogens is increasing in many countries due to increasing age, the prevalence of chronic diseases and immuno-suppressive conditions, therefore the need for strict food safety standards from the farm to the table. The use of artificial intelligence from farm to table is meant to reduce wide range of sanitary and phyto-sanitary issues that has been highlighted by many authors and this could lead to national development by reducing hunger, poverty and food borne diseases. It will also increase the economic status of the society. Industrializing cashew apples, specifically for the purpose of producing juice, jams, preserves, jelly and whole or diced dehydrated fruits, is a handy alternative to add value to products and generate income to cashew farmers in Nigeria due to the fact that they can be preserved for months without undergoing any undesirable changes, thus maintaining their organoleptic properties, such as aroma, taste, texture and color, besides, what is mostly important, their nutritional values are kept at high levels [24, 25, 26].

Development is a critical factor and a desirable phenomenon in the sustenance and growth of any nation [27], an encompassing process involving the steady and systematic change in the cultural, economic and political spheres of society in a way that increases production, empowers the people and their communities, protects the environment, strengthens institutions, grows quality of life and promotes good governance [28]. National development includes controlling human impacts on the environment, it requires efforts made to eliminate poverty and reduce the number of hungry people. It is believed that the poverty in Nigeria is as a result of corruption and negative attitudes of Nigerians towards the development of the nation. In Nigeria overpopulation and the depletion of natural resources, food security, overexploitation of ecosystems for direct use and non-use utility are among the human-environmental issues which have created social, economic and ecological injustice, different forms of innovations are therefore needed for technological development which is the base for national development. One of such innovation is the use of artificial intelligence in the production of quality cashew juice.

\section{Material and methods}

The cashew apple juice was obtained through mechanical process. This juice, which contains high levels of tannins, was clarified by adding gelatin to remove tannins and suspended solids. The clarified cashew apple juice was filtered, physico-chemically characterized.

\subsection{Collecting and processing of cashew apples}

Cashew apples were collected from Federal College of Education, Okene, Kogi State compound. When cashews are brought from the field, they generally have high microbial load, due to their contact with the ground and handling. The 
ripe fruits were weighed, washed thoroughly with $3 \%$ salt solution followed by distilled water, this is aimed at reducing the microbial load on the surface of fruits, the fruits are then soaked in sodium hypochlorite solution 10 minutes in a concentration of $200 \mathrm{ppm}(0.02 \%)$ of active chlorine and good quality cashew apples were sorted for processing.

\subsection{Processing of cashew apple juice}

Continuous hydraulic press made of stainless steel equipped with a screw that spins and crushes the apples, was used to extract the juice as it is more efficient and productive as well as avoid excessive release of tannins due to the abrasive force caused when apples come in contact with the sides of the screw. An efficient method of clarification by [26, 29] was used. Watery solution of Gelatine with $10 \%$ concentration ( $1 \mathrm{~g}$ of gelatine $/ 100 \mathrm{ml}$ of water) this was heated to the temperature of $50^{\circ} \mathrm{C}$ this allows the gelatine to dissolve in the water. The gelatine solution is added to juice little by little, pouring a thread of the solution into the juice, this was constantly stirred until the colour changed to milky and precipitates were formed. The juice was then filtered carefully using a series of filters, Whattman and Millipore membrane filters of pore size $0.44 \mu \mathrm{m}$ and $0.22 \mu \mathrm{m}$ under sterile environment until clear, clarified, colourless, transparent and glossy juice was obtained. Citric acid and benzoic acid at a concentration of $0.1 \mathrm{~g} / \mathrm{L}$ each were added to juice and transferred to sterilized glass bottles. Replicate samples were refrigerated and analyzed for juice quality at an interval of 30 days. Fresh cashew apple juice was used as the control sample.

\subsection{Shelf life study}

The shelf life of the juice is studied in terms of sensory, physico-chemical and microbiological quality.

\subsection{Sensory evaluation.}

Sensory evaluation is unique source of product information concerned with measuring the response of people to products in terms of appearance, aroma, taste, texture and after taste without benefit of label, pricing or other imagery [30]. Three samples of the juice (fresh juice, juice stored under ambient conditions and refrigerated juice) was judged for mouth feel, colour, flavour, taste, sedimentation and overall acceptability. Ambient storage duration was for 24 hrs and refrigerated storage was at $5^{\circ} \mathrm{C}[12,31]$. The juices were served to 20 students from the Department of Biology in Federal College of Education, Okene. With fresh juice as control, the sensory attributes of juice under ambient storage was compared with juice under refrigerated storage. The hedonic scale rating was used to assess the likability and acceptability of both the fresh juice and preserved juice. The scale ranges from one through nine with one being "dislike extremely," five being "neither like nor dislike," and nine being "like extremely." The means of the scores by the judges were tested by analysis of variance for significant differences $(\mathrm{p} \leq 0.05)$ between their respective juice samples.

\subsection{Physico-chemical analysis}

The $\mathrm{pH}$ of the cashew juice was measured using a standard pH meter (PHYWE, range 0-14). The pH of 7 after which the bulb was dipped in another buffer solution and the reading on the scale was adjusted. The bulb was dipped into the juice samples and the $\mathrm{pH}$ reading of the juice was repeated 3 times and the average were recorded.

The colour and clarity of the juice were analysed using spectrophotometer and absorbance values of the juice determined at $450 \mathrm{~nm}$ and $600 \mathrm{~nm}$ wave length. The measurement was made by inserting the coveter (glass tube) containing the samples into the light path of the spectrophotometer which measured the intensity of light at various wave lengths transmitted by the solution. The intensity of light was determined by the electric detector, which converted radiant energy to electric energy. The diluted juice samples which had the absorbance value at $450 \mathrm{~nm}$ was used as a standard and the other filled with the juice were inserted into the instrument and knob was switched off before taking the reading of the absorbance on the electronic scale.

Viscosity in centipoises was determined using Ostwald's viscometer. Vitamin C content as mg/100 ml, total and reducing sugars as \% were determined using a refractometer. The sample was poured on the sample holder and covered. The readings was taken directly from the scale when viewed from the eye-piece after adjusting the knob until there was a clear demarcation between yellow and light by a red light which the red line was at the centre of the cross. The analysis was carried out for the respective samples and recorded.

The specific gravity of the juice samples were measured by the use of hydrometer. The hydrometer was dropped into the juice sample when it was cooled at $20^{\circ} \mathrm{C}$ after extraction in a measuring cylinder and was allowed to float. The readings were taken directly from the hydrometer scale by reading the upper meniscus. This was measured by using $0.1 \mathrm{~N} \mathrm{NaOH}$ solution and phenolphthalein indicator. The juice sample $(25 \mathrm{ml})$ was diluted to about $25 \mathrm{ml}$ with distilled water. One hundred milliliter solution of the sample was titrated with $0.1 \mathrm{~N} \mathrm{NaOH}$ per $100 \mathrm{ml}$ of original solution. This values were then converted to percentage titratable acidity using a standard formular. 


\subsection{Microbiological analysis}

The numbers of micro-organisms (bacteria, yeasts and molds) present in the fruit juice were determined using the pour plate count method a recommended in the International Commission on Microbiological Specification for Foods [32]. The pipettes and plates were sterilized by autoclaving at $121^{\circ} \mathrm{C}$ before use and hygienically stored. The agar (potato dextrose) was prepared. Appropriate serial dilutions of the samples were carried out and then the agar was allowed to cool to $15^{\circ} \mathrm{C} .0 .1 \mathrm{ml}$ of the selected dilution was spread on triplicate plates using sterile glass spreader. The plates were covered immediately and gently shaken, then placed at $37^{\circ} \mathrm{C}$ for $24-48 \mathrm{hrs}$. The microbial growth on each of various sample plates were counted and recorded. This was repeated at one week interval for (4) weeks.

Total count = Initial dilution $\mathrm{x}$ subsequent $\mathrm{x}$ Amount of plated = Dilution Factor.

\section{Results and discussion}

The cashew apples from the field yielded $840 \mathrm{ml} / \mathrm{kg}(80 \%)$ juice. Fresh juice was viscous but after clarification (with gelatine) and filtration it was observed that the juice became clear without any turbidity, this shows the decrease in viscosity (1.398 to $1.258 \mathrm{cps}$ ) indicating better physical stability of the juice which was found to be stable for the 30 days under study. Clarification was necessary as it clears the juice by reducing the suspended solids and lowers the tannin concentration.

\subsection{Sensory evaluation}

Fresh cashew apple juice was light yellow in colour. The colour of Sample A (the untreated fresh juice) became darker on daily bases during storage. Within the first two weeks of storage, the samples became very dark due to the action of non-enzymic browning reaction in the juice during storage, whereas the treated juice (clarified + preservatives) after filtration was colourless throughout the storage period this could be due to the gelatine action and preservatives (Citric acid and benzoic acid) added to the juice. The colour of sample B (clarified and preserved with Citric acid), $\mathrm{C}$ (clarified and preserved with benzoic acid) and D (clarified and preserved with both Citric acid + benzoic acid) did not change as they maintained colourless and clear juice for 30 days, without cloudiness, haze or precipitation. This maintenance of colour could be attributed to the clarification and the preservative effects on the juice samples which inactivated enzyme browning in the juice.

Table 1 The colour of cashew juice samples under 30 days of storage

\begin{tabular}{|l|l|l|l|}
\hline Sample & $\begin{array}{l}\text { Fresh } \\
\text { Juice }\end{array}$ & \multicolumn{2}{|l|}{ Stored Juice } \\
\hline & $\left(28^{\circ} \mathrm{C}\right)$ & $\begin{array}{l}\text { Refrigerated Juice } \\
\left(5^{\circ} \mathrm{C}\right)\end{array}$ & $\begin{array}{l}\text { Juice under ambient storage } \\
\left(28^{\circ} \mathrm{C}\right)\end{array}$ \\
\hline Untreated juice (Sample A) & 0.17 & 0.17 & 0.17 \\
\hline $\begin{array}{l}\text { Clarified and preserved with Citric acid } \\
\text { (Sample B) }\end{array}$ & 0.17 & 0.16 & 0.50 \\
\hline $\begin{array}{l}\text { Clarified and preserved with benzoic acid } \\
\text { (Sample C) }\end{array}$ & 0.17 & 0.16 & 0.40 \\
\hline $\begin{array}{l}\text { Clarified and preserved with Citric acid + } \\
\text { benzoic acid (Sample D) }\end{array}$ & 0.17 & 0.17 & 0.51 \\
\hline
\end{tabular}

When spectrophometric test for absorbance was carried out as shown in Table 1, the result gave 0.17 for the first day. When stored for 30 days, samples B, C and D recorded absorbance value of $0.16,0.16$ and 0.17 respectively when stored under low temperature and increased in the absorbance values when stored in room temperature compared to low temperature storage and recorded $0.50,0.40$ and 0.51 respectively. 
Table 2 Sensory evaluation of cashew juices under ambient and refrigerated storage in 24 hours

\begin{tabular}{|l|l|l|}
\hline Sensory attributes & Juice under ambient storage & Refrigerated Juice \\
\hline Mouth feel & 1.56 & 2.41 \\
\hline Colour & $3.21^{*}$ & $3.08^{*}$ \\
\hline Flavour & 1.50 & 2.35 \\
\hline Taste & $2.89^{*}$ & $2.46^{*}$ \\
\hline Sedimentation & 2.35 & 3.20 \\
\hline Overall acceptance & $2.59^{*}$ & $1.56^{*}$ \\
\hline
\end{tabular}

The results in Table 2 indicated a significant difference $(\mathrm{p}<0.05)$ between the colour, taste and acceptability of juice under ambient storage and the refrigerated juice, while there was no significance difference between mouth feel, flavour and sedimentation.

Table 3 Mean scores of sensory acceptance of fresh and preserved cashew apple juice

\begin{tabular}{|l|l|l|l|l|l|l|}
\hline Attribute & Fresh juice & \multicolumn{5}{|l|}{ Clarified and preserved sample with Citric acid + } \\
benzoic acid & \multicolumn{5}{l|}{} \\
\hline Storage time (in days) & & Day 1 & Week 1 & Week 2 & Week 3 & Week 4 \\
\hline Colour & 4.0 & $9.0 *$ & 8.5 & 8.5 & 8.5 & 8.5 \\
\hline Flavour & 7.5 & 7.5 & 7.0 & 7.0 & 6.5 & 6.5 \\
\hline Taste & 4.5 & $8.0 *$ & 8.0 & 7.5 & 7.0 & 7.5 \\
\hline Sedimentation & 7.5 & 7.5 & 7.5 & 7.0 & 7.5 & 7.0 \\
\hline Overall acceptance & 8.5 & 9.0 & 8.5 & 8.0 & 7.5 & 7.0 \\
\hline
\end{tabular}

The hedonic scale rating of both the fresh juice as well as preserved juice was 9.0 for likability or the acceptability of both the samples. The mean sensory scores of the juice presented significant difference in taste and colour up to 30 days (Table 3). This could be due to decrease in tannins causing astringency and the removal of coloured pigments from the fresh juice as a result of clarification. There was no significant difference in sedimentation, flavour and overall acceptability throughout the storage period, indicating the effectiveness of the preservation method in retaining sensory attributes.

\subsection{Physico-chemical analyses}

Clarity of the juice indicates good appearance and acceptability.

Table 4 Significant changes in important physico-chemical characteristics of preserved cashew apple juice

\begin{tabular}{|c|c|c|c|c|c|}
\hline $\begin{array}{l}\text { Storage time } \\
\text { (in days) }\end{array}$ & $\mathbf{p H}$ & $\begin{array}{l}\text { Total sugars } \\
(\%)\end{array}$ & $\begin{array}{l}\text { Vitamin C } \\
(\mathrm{mg} / \mathbf{1 0 0} \mathrm{ml})\end{array}$ & $\begin{array}{l}\text { TSS } \\
(\%)\end{array}$ & $\begin{array}{l}\text { Tannin content } \\
(\%)\end{array}$ \\
\hline 0 (fresh juice) & $3.40^{*}$ & 9.60 & 190.00 & 15.5 & $0.58^{*}$ \\
\hline 7 & $3.33^{*}$ & 9.62 & 190.00 & 15.7 & $0.42^{*}$ \\
\hline 14 & $3.20^{*}$ & 9.61 & 190.00 & 15.9 & $0.38^{*}$ \\
\hline 21 & $3.15^{*}$ & 9.59 & 190.20 & 16.2 & $0.23^{*}$ \\
\hline 30 & $3.10^{*}$ & 9.60 & 190.20 & 16.0 & $0.20^{*}$ \\
\hline
\end{tabular}


The results of physico-chemical evaluations are as shown in Table 4. The pH which influences palatability of the preserved juice decreased from 3.40 to 3.10 up to 30 days. This decrease in pH could be as a result of the action of citric acid and benzoic acid. Most of the bacteria will not grow at low $\mathrm{pH}$ and hence good keeping quality of the juice is maintained [32]. A significant difference $(\mathrm{p}<0.05)$ exists in the specific gravity, $\mathrm{pH}$ and vitamin $\mathrm{C}$ content of the juice stored under ambient storage.

Total and reducing sugars in the preserved juice were stable up to a period of 30 days. Total soluble solids content (TSS) of fruit juices detect the level maturity of fruits used for making juice. Total soluble solids of the juice were stable in the range of $15.5-16.0 \%$ Brix for the 30 days showing that the fruits were collected at mature stage. This might be the reason for good palatability and acceptability of the juice, as can be deduced from the fact that reducing sugars are the main constituents of soluble solids. This agrees with $[15,26,29]$ who reported on the production various ways of producing cashew juice

Vitamin C content of the juice was found to be $190 \pm 1.0 \mathrm{mg} / 100 \mathrm{ml}$ and was stable throughout the 30 days, a slight decrease noted in vitamin $\mathrm{C}$ could be due to oxidation, which occurs in fruit juices during storage and is highly dependent on the presence of oxygen in the head space or dissolved in the juice.

\subsection{Microbial analysis}

Table 5 Microbial quality of the preserved cashew apple juice

\begin{tabular}{|l|l|l|l|l|l|l|}
\hline \multirow{2}{*}{ No. of days } & \multicolumn{2}{|l|}{ Fresh juice } & \multicolumn{3}{l}{$\begin{array}{l}\text { Clarified and preserved sample with Citric } \\
\text { acid + benzoic acid }\end{array}$} \\
\cline { 2 - 8 } & $\begin{array}{l}\text { Bacteria } \\
\text { CFU/ml) }\end{array}$ & $\begin{array}{l}\text { Yeasts } \\
\text { CFU/ml) }\end{array}$ & $\begin{array}{l}\text { Molds } \\
\text { CFU/ml) }\end{array}$ & $\begin{array}{l}\text { Bacteria (in } \\
\text { CFU/ml) }\end{array}$ & $\begin{array}{l}\text { Yeasts (in } \\
\text { CFU/ml) }\end{array}$ & $\begin{array}{l}\text { Molds } \\
\text { CFU/ml) }\end{array}$ \\
\hline 0 & $<5$ & $<10$ & No growth & No growth & No growth & No growth \\
\hline 1 & $<5$ & $<10$ & No growth & No growth & No growth & No growth \\
\hline 8 & $5>$ & $10>$ & No growth & No growth & No growth & No growth \\
\hline 15 & $5>$ & $<15$ & $<1$ & No growth & No growth & No growth \\
\hline 21 & $<15$ & $<15$ & $<1$ & No growth & No growth & No growth \\
\hline 28 & $15>$ & $15>$ & $<5$ & No growth & No growth & No growth \\
\hline 30 & $15>$ & $15>$ & No growth & No growth & No growth \\
\hline
\end{tabular}

The microbiological count of fresh cashew apple juice was found to be higher $(<15)$. The initial presence of microorganisms in fresh cashew apple juice could be due to the presence of sugars. When the juice was subjected to sterile filtration, complete removal of microorganisms was observed and the juice quality was stable up to 30 days (Table 5).

\section{Conclusion}

Results obtained from the investigations on extraction and preservations of cashew juice using citric and benzoic acid as preservatives concluded that citric acid and benzoic acid are good preservatives for cashew fruit juice, it also confirmed that the used of stainless manual extractor as well as the combination of clarification, sterile filtration and chemical preservation is suitable for preservation of cashew apple juice up to 30 days under refrigeration. This method was efficient in decreasing astringency, microbial count and in retaining nutrient quality of the juice, since soluble solids, total sugar content and vitamin $\mathrm{C}$ were no affected significantly. The juice was also acceptable in terms of sensory attributes. Further, the method described is simple, rapid, inexpensive and convenient for industrial use in the processing and preservation of cashew apple juice. The utilization of the preserved juice should be encouraged as health drink and could be recommended to people with vitamin C deficiency because of its high vitamin C content. Above all, preservation of cashew apple juice is important because of the seasonality of its production which makes it abundantly available during its season and scarce during off season. Stability of shelf-life indicated that the colour, $\mathrm{pH}$, specific gravity, total soluble solid (Brix level) and titratable acidity of the cashew juice was stable during storage when preserved with citric acid and benzoic acid. It is therefore recommended that cashew be processed with other fruits to make blends of juices due to its high ascorbic acid content. 


\section{Compliance with ethical standards}

\section{Acknowledgments}

I am sincerely grateful to the Department of Biology and the Department of Agricultural Sciences both in Federal College of Education, Okene, Kogi State, Nigeria whose garden contained the Cashew plantation where the cashew apple were picked from, the Laboratory technician who helped in the analysis of the juice is highly appreciated. I am also grateful to all the authors whose materials were used in the process of this research work.

\section{References}

[1] Shalini K, Vinay S, Sirivasta G, Shiva G. Cashew Hand Book 2014 - Global perspective” in association with African cashew alliance wwwcashewrryor.com (4th edition. Published foretell business solution provate limited. India. 2014

[2] Chempakam B. Distribution of ascorbic acid and ascorbic acid oxidase activity in the developing cashew apple (Anacardiumoccidentale L.). J. Hortic. Sci. 1983; 58:447-448.

[3] Campos DCP, Santos AS, Wolkoff DB, Matta VM, Cabral LMC, Couri S. Cashew apple juice stabilization by microfiltration. Desalination. 2002; 148: 61-65.

[4] Umoru AM, Agbulu ON. Skills required by secondary school leavers for cashew (Anacadiumoccidentalis L) production in Kogi state, Nigeria. International Journal of Agricultural and Home Economics Education. 2017; 4 (1):129 - 137.

[5] Kubo I, Muroi H, Himejima M. Structure-antibacterial activity relations of anacardic acids. J. Agric. Food Chem.1993; 41:1016-1019.

[6] Melo-Cavalcante AA, Rubensam G, Picada JN, da Silva EG, Moreira FJC, Henriques JAP. Mutagenicity, antioxidant potential and antimutagenic activity against hydrogen peroxide of cashew (Anacardium occidentale) apple juice and cajuina. Env. Mol. Mutagen.2003; 41:360-369.

[7] Oliveira AHS.; Ogrodowski CS, Goncalves LRB Santana MHA. Natural cashew apple juice as fermentation medium for hyaluronic acid production by Streptococcus zooepidemicus. Proceedings of the 27th Symposium on Biotechnology for fuels and chemicals. Poster presentation 5-17. Research, Royal Tropical Institute, Amsterdam. 2005

[8] Rocha, MVP, Oliveira AHS, Souza MCM, Goncalaves LRB. Natural cashew apple juice as fermentation medium for biosurfactant production by Acinetobacter calcoaceticus. World Journal of Microbiology and Biotechnology. 2006; 22:1295- 1299 .

[9] Chagas CMA, Honorato ET, Pinto EGAS, Maia EGA, Rodrigues S. Dextransucrase production using cashew apple juice as substrate: effect of phosphate and yeast extract addition. Bioproc. Biosys. Eng. 2007; 30:207-215.

[10] Pinheiro ADT, Rocha MVP, Macedo GR, Goncalves LRB. Evaluation of cashew apple juice for the production of fuel ethanol. Applied Biochemistry and Biotechnology 2008; 148: 227 - 234.

[11] Fontes CPML, Honorato TL, Rabelo MC, Rodrigues S. Kinetic study of mannitol production using cashew apple juice as substrate. Bioproc. Biosys. Engg. 2009; 32:493-499.

[12] Ogunsina BS, Lucas EB. The development of a manually operated cashew juice extractor. Journal of biomedicine and biotechnology. 2008; 5:332 - 350. Agriculture Engineering International: The CIGR Ejournal. Vol.X. Manuscript FP 07037.

[13] Nwosu CS., Adejumo OA., Udoha WN. Cashew apple utilization in Nigeria Challenges and prospects. Journal of Stored Products and Postharvest Research. 2016; 7(2):29 - 31.

[14] Azevedo DCS, Rodrigues AE. Obtainment of high-fructose solutions from cashew (Anacardiumoccidentale, L.) apple juice by SMB chromatography. Sep. Sci. Technol. 2000; 35:2561-2581.

[15] Pushpalatha PB, Sobhana A, Mini C. Processing and product diversification in cashew apple. Advances in Cashew Production Technology.Lecture Notes Series 2015; 24:109 - 116.

[16] Costa MCO, Maia GA, Wilane de Figuiredo, R, Filho, MM, Brasil IM. Storage stability of cashew apple juice preserved by hot fill and aseptic processes. Ciência e tecnologia de Alimentos. 2003; 23 (Supl):106-109. 
[17] Azoubel PM, El-Aouar EA, Tonon RV, Kurozawa LE, Antonio GC, Murr FEX, Park KJ. Effect of osmotic dehydration on the drying kinetics and quality of cashew apple. Int. J. Food Sci. Tech. 2009; 44:980-986.

[18] Bhat MG, Nagaraja KV, Rupa TR. Cashew research in India. J. Hortl. Sci. 2010; 5:1-16.

[19] Uma T, Rama RV, Khasim BS. Preservation and Shelf life Extension of Cashew Apple Juice. Internet Journal of Food Safety.2011; 13:275 - 280.

[20] Xu J, Yang P, Xue S, Sharma B, Sanchez-Martin M, Wang P, Beaty K A, Dehan E, Parikh B. Translating cancer genomics into precision medicine with artificial intelligence: applications, challenges and future perspectives Springer. 2019

[21] Dilsizian SE, Siegel EL. Artificial intelligence in medicine and cardiac imaging: harnessing big data and advanced computing to provide personalized medical diagnosis and treatment. CurrCardiol Rep 2014; 16:441 doi:10.1007/s11886-013-0441-8 [PubMed] [Google Scholar]

[22] Jiang F, Jiang Y, Zhi H, Dong Y, Li, H, Ma, S, Wahg Y, Dong Q, Shen, H, Wangyong H. Artificial intelligence in healthcare: past, present and future. Journal of Neurointerventional Surgery. 2017; 2(4):230 - 244. Stroke and Vascular Neurology. 2017:2doi:10.1136/svn-2017.000101

[23] Karl LB. Data - centric and logic - based models for automated legal problem solving. Artificial intelligence and law. 2017; 25 (1):5 - 27.

[24] Oduwole, O0, Akinwale, TO, Olubamiwa, O. Economic evaluation of a locally fabricated extraction machine for a cottage cashew juice factory. The Journal of Food Technology in Africa, Nairobi, Kenya. 2001; 6(1):18-20

[25] Jatto WO, Adegoke GO. Storage studies on cashew juice preserved with water extracted Aframomum danielli. Elect. J. Env. Agri. Food Chem.2010; 9:1351-1359. 280

[26] Francisco Fábio de AssisPaiva 2013. Improving cashew nut post harvest technologies in Tanzania. Technical Manual.Brazilian Agricultural Research Corporation- Embrapa

[27] Lawal, T., Oluwatoyin, A. "National Development in Nigeria: Issues, Challenges and Prospects", Journal of Public Administration and Policy Research, 2011; Vol. 3, No. 9:pp. 237-241.

[28] Woleola JE, National development in Nigeria and the indispensable lessons for Nigeria to learn from the Asian tigers.Journal of Good Governance and Sustainable Development in Africa (JGGSDA),2015:2(4):10 - 16.

[29] Honorato TL., Rabelo MC., Gonc, alves LR.B., Pinto GAS., Rodrigues S. Fermentation of cashew apple juice to produce high added value products. World Journal of Microbiology and Biotechnology. 2007; 23:1409-1415. DOI 10.1007/s11274-007-9381-z

[30] Evanie DD, Karl, R., Sunny I. The production of bioethanol from cashew apple juice by batch fermentation using saccharomyces cerevisiae Y2084 and Vin13. Renewable and Sustainable Energy. 2013; 17 (1):11

[31] Laguerre, O., Derens, E., Palagos, B. Study of domestic refrigerator temperature and analysis of factors affecting temperature: A French survey. International Journal of Refrigeration.2002; 5:653-659

[32] Ranganna S. Handbook of analysis and quality control for fruit and vegetable products. (2nd edition). New Delhi: McGraw Hill, 1986; pp. 9, 80. 